\title{
Eventos extremos de precipitação no sertão paraibano: Variação espaço-temporal
}

\section{Extreme events of precipitation in the paraibano sertão: Space-temporary variation}

\author{
Jaricélia Patrícia de Oliveira Sena ${ }^{1}$; Daisy Beserra Lucena ${ }^{2}$; George do Nascimento Ribeiro ${ }^{3}$
}

Resumo: A variabilidade pluviométrica é característica marcante na região semiárida, não somente nos totais anuais, como também na quantidade e distribuição espacial. Com o objetivo de contribuir para o entendimento dos eventos extremos de precipitação na região semiárida da Paraíba, foi identificado anos de eventos extremos na microrregião do Sertão paraibano, utilizando o Índice de Anomalia de Chuva (IAC). Os dados utilizados foram provenientes do CPC (Climate Prediction Center), centro pertencente ao NCEP (National Centers for Environmental Prediction), compreendendo o período de 19792013. Os resultados mostram a distribuição têmporo-espacial bastante homogênea em relação aos eventos extremos, ou seja, os anos chuvosos ou secos, quando ocorrem atingem toda a microrregião. Observou-se que no painel anual um período bem pequeno de precipitação, considera-se o período chuvoso e após este período percebe-se que ocorre uma diminuição drástica na precipitação. Dos 35 anos analisados de precipitação, verificou-se que 19 anos apresentaram precipitações abaixo da média climatológica $(54,3 \%)$ e 16 anos com precipitações acima da média (45,7\%). A contribuição dos meses que não compõe o período chuvoso para a microrregião do Sertão Paraibano (maio a janeiro), apresentou-se de forma significativa nos eventos chuvosos, entretanto, para os eventos secos não teve nenhuma contribuição. A variação espacial da precipitação na região tanto para a climatologia, quanto para as composições dos anos selecionados como secos e chuvosos, apresenta distribuição no sentido Leste-Oeste, com amplitudes altas, comprovando a variação espacial.

Palavras-chave: Painel têmporo-espacial; IAC; Semiárido

\begin{abstract}
Rainfall variability is a striking feature in the semi - arid region, not only in annual totals, but also in quantity and spatial distribution. In order to contribute to the understanding of extreme precipitation events in the semi - arid region of Paraíba, it was identified years of extreme events in the Sertão Paraíba micro - region, using the rainfall anomaly index (IAC). The data used came from the CPC (Climate Prediction Center), a center belonging to the NCEP (National Centers for Environmental Prediction), covering the period 1979-2013. The results show a very homogeneous temporo-space distribution in relation to the extreme events, that is, the rainy or dry years, when they occur reaches the entire microregion. It was observed that in the annual panel a very small precipitation period, it is considered the rainy season and after this period a drastic decrease in precipitation occurs. Of the 35 analyzed years of precipitation, it was verified that 19 years presented rainfall below the climatological average $(54.3 \%)$ and 16 years with precipitations above the average (45.7\%). The contribution of the months that do not compose the rainy season to the Sertão Paraibano microregion (May to January - 9 months), presented in a significant way in the rainy events, however, for the dry events had no contribution. The spatial variation of the precipitation in the region for both the climatology and the compositions of the years selected as dry and rainy, shows a distribution in the east-west direction, with high amplitudes, proving the spatial variation.
\end{abstract}

Key words: Temporo-spacial panel; IAC; Semiarid

\footnotetext{
*Autor para correspondência

Recebido para publicação em 13/06/2017; aprovado em 30/09/2017

${ }^{1}$ Engenheira de Biossistemas, Doutoranda do Programa de Pós-Graduação em Engenharia Agrícola, Universidade Federal de Campina Grande, Campina Grande, Paraíba . E-mail: jariceliasena@ hotmail.com

${ }^{2}$ Professora Adjunta . Departamento de Geociências , Centro de Ciências Exatas e da Natureza, Universidade Federal da Paraíba, João Pessoa, Paraíba. E-mail: daisylucena@yahoo.com.br

${ }^{3}$ Dr. em Engenharia Agrícola, Prof. Adjunto, Centro de Desenvolvimento Sustentável do Semiárido, Universidade Federal de Campina Grande, Sumé, Paraíba. E-mail: george@ufcg.edu.br
} 


\section{INTRODUÇÃO}

Nas últimas décadas os eventos extremos, dentre os quais podem citar: o período de estiagem, inundações, deslizamentos e etc., têm afetado diversas cidades brasileiras causando múltiplos e constantes impactos, tais como: elevado número de mortes, feridos, desabrigados, proliferação de doenças, perdas econômicas, impactos ao meio ambiente, dentre outros. Esses impactos são ainda mais susceptíveis a população que vive em situação de vulnerabilidade (LOUREIRO et al.,2014).

A atmosfera segue um ritmo composto por eventos usuais (normais) e eventos extremos (anômalos). Gonçalves (2013) comenta que, os eventos usuais são facilmente absorvidos pela sociedade, pois ocorrem com maior frequência e não se afastam significativamente das normais climatológicas, entretanto, os eventos extremos de chuva, por exemplo, são aqueles em que os totais em certo período - seja anual, sazonal, diário, ou outro - apresentam desvios de chuva superiores ou inferiores ao comportamento habitual da área no período analisado e, geralmente, apresentam consequências na área onde ocorrem.

Segundo Marengo (2002), algumas das consequências causadas pela mudança climática, associadas ao aquecimento global, provocam alterações nos eventos extremos de chuva, na intensidade da chuva e períodos secos mais longos e frequentes. Eventos extremos de precipitação, seja em excesso ou déficit, têm sido uma das mudanças do clima que mais contribuem para ocorrência de desastres naturais em várias regiões do Brasil (MARENGO, 2010).

$\mathrm{Na}$ região Semiárida brasileira a variabilidade do regime pluviométrico é característica marcante, não somente nos totais anuais, como também na quantidade e distribuição espacial. Por exemplo, na Paraíba a variação espacial é enorme, no interior do estado a precipitação anual, normalmente, é inferior a $800 \mathrm{~mm}$, enquanto na parte litorânea os totais anuais superam os $1500 \mathrm{~mm}$ (SILVA et al., 2003).

Sendo assim, a caracterização, análise e entendimento do comportamento (variações) das chuvas, visando destacar possíveis periodicidades existentes, fenômenos que podem influenciar, bem como, identificação de áreas susceptíveis a ocorrência de eventos extremos de chuvas, são fundamentais para o planejamento de inúmeras atividades agropecuárias, gestão dos recursos hídricos (abastecimento público de água), atividades econômicas e sociais, dentre outras (SILVA et al., 2005). Ademais, no contexto das mudanças climáticas, previsões alertam que esses eventos tendem a aumentar de intensidade (BRASIL, 2005).

No Sertão Paraibano, foco deste estudo, a precipitação é um fator de extrema importância no que diz respeito às condições do clima local, para o desenvolvimento econômico, social, cultural; em outras palavras, a água é um fator crítico para as populações dessa região, que dependem direta ou indiretamente desta variável.

Um dos métodos para selecionar os eventos extremos de chuva é o Índice de Anomalia de Chuva (IAC), que tem se revelado como uma importante e potencial ferramenta de análise das precipitações, na determinação de anomalias extremas e para aplicações de monitoramento, tendo em vista a simplicidade e facilidade de procedimento, devido ao auxilio dos recursos computacionais (planilhas eletrônicas), além do acesso aos dados de precipitação mensais em tempo real (SANCHES et al., 2014; REPELLI et al., 1998).

Não obstante, segundo os autores, este índice parece ser apropriado para a utilização em regiões semiáridas e ou tropicais, especialmente para o Nordeste do Brasil. Neste sentido, vários estudos como os de Repelli et al.(1998), Freitas (2004) e (2005), Gonçalves et al. (2006), Silva (2007) e Chechi e Sanches (2013) analisaram os eventos extremos sobre diversas regiões do Nordeste do Brasil utilizando o IAC, destacando-se os de Wanderley et al. (2012) e Araújo et al. (2009) que realizaram os estudos para a região Semiárida nordestina.

Com isso objetivou-se contribuir para o entendimento dos eventos extremos de precipitação na região semiárida da Paraíba, identificando anos de eventos extremos na microrregião do Sertão Paraibano, utilizando o Índice de Anomalia de Chuva (IAC).

\section{MATERIAL E MÉTODOS}

\section{Área de Estudo}

O Estado da Paraíba esta situado no extremo leste da região Nordeste do Brasil, com uma área de $56.372 \mathrm{~km}^{2}$, entre os meridianos de $34^{\circ} 45^{\prime} 54^{\prime \prime}$ e $38^{\circ} 45^{\prime} 45^{\prime \prime}$ de longitude oeste e entre os paralelos de $6^{\circ} 02^{\prime} 12^{\prime \prime}$ e $8^{\circ} 19^{\prime} 18^{\prime \prime}$ de latitude sul, possui ao todo 223 municípios (IBGE, 2010; FRANCISCO, 2010).

O foco desse trabalho, o Sertão Paraibano, esta localizado no extremo oeste do estado e é composto por 48 municípios (Figura 1). É uma região semiárida, caracterizada de forma geral, pela aridez do clima, deficiência hídrica, solos pobres, temperaturas elevadas e fortes taxas de evapotranspiração (SILVA, 2006).

O relevo do Estado da Paraíba apresenta-se de uma forma geral, bastante diversificado, constituindo-se por formas de relevo diferentes. A geomorfologia da região de estudo está sob o Setor Ocidental Subúmido e Semiárido, em Áreas cristalinas que compreendem o Pediplano Sertanejo e Áreas Sedimentares Continentais, correspondendo às Chapadas e Depressão do Rio do Peixe. Com relação à geologia, $89 \%$ de sua área se estabelece sobre rochas précambrianas, sendo complementada por bacias sedimentares fanerozóicas, rochas vulcânicas cretáceas, coberturas plataformais paleógenas/neógenas e formações superficiais quaternárias (PARAÍBA, 2006).

A vegetação é formada principalmente por plantas xerófitas cuja denominação mais comum é de caatinga, instituída de cactos, jurema e outras muito resistentes a longos períodos de estiagens. O clima da região é semiárido, quente seco, sendo semiúmido nas áreas que apresentam serras e depressões, com precipitações de verão, sucedendo nos meses de fevereiro a maio, resultantes da zona de convergência intertropical e temperaturas médias anuais superiores a $24^{\circ} \mathrm{C}$ (LIMEIRA, 2008). O uso atual e a cobertura vegetal caracterizam-se por formações florestais definidas como caatinga arbustiva arbórea aberta, caatinga arbustiva arbórea fechada, caatinga arbórea fechada, tabuleiro costeiro, mangues mata úmida, mata semidecidual, mata atlântica e restinga (PARAÍBA, 2006). 
Figura 1. Localização do Sertão paraibano e seus respectivos municípios

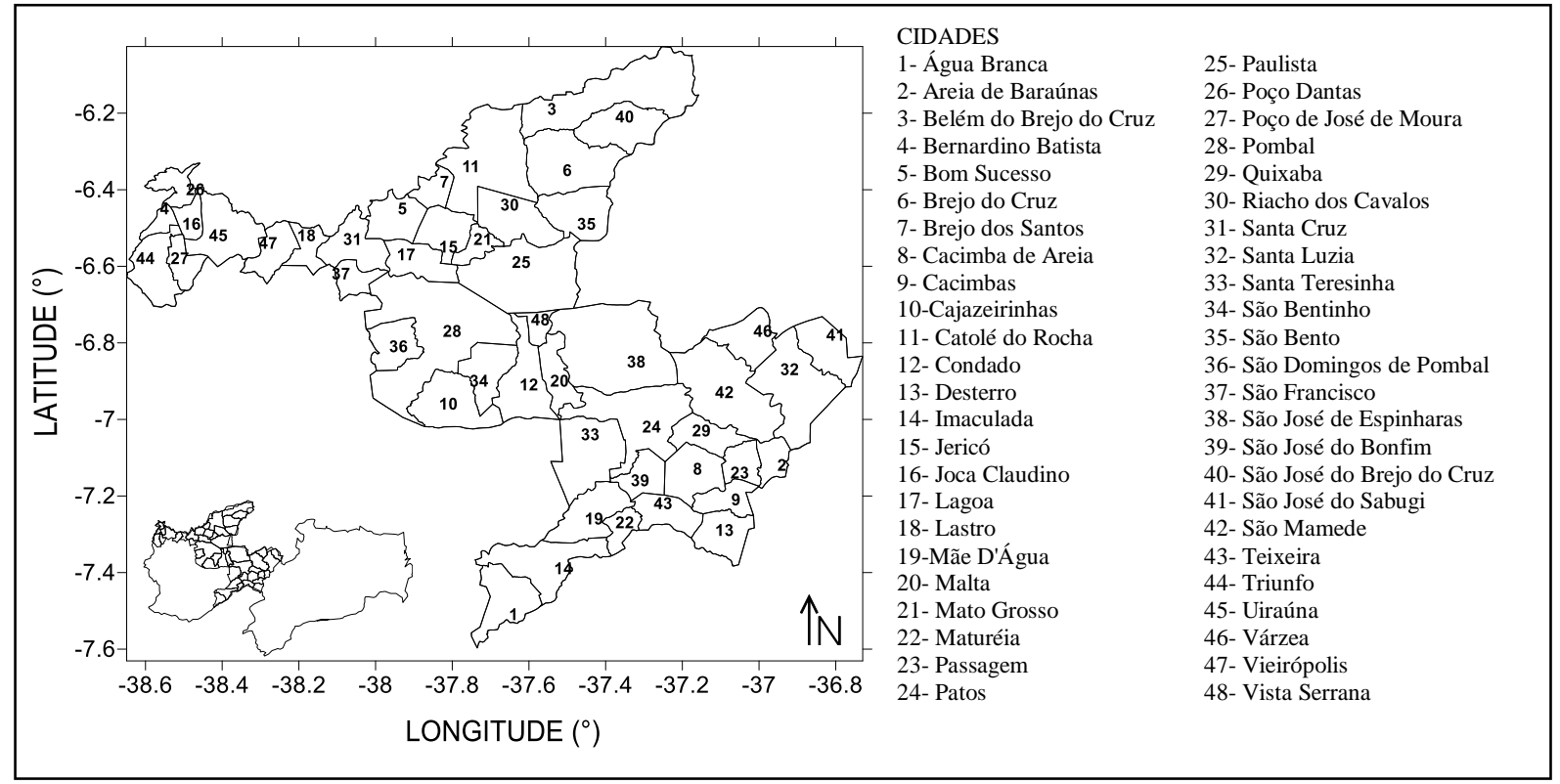

Fonte: Melo (2015)

É uma região que apresenta irregularidade pluviométrica tanto espacial quanto temporal, além dos eventos de secas que afeta a região. A agricultura e pecuária são pouco desenvolvidas, sendo o setor comercial a principal fonte de renda da microrregião do Sertão paraibano. Silva et al. (2003) reportam que, a variabilidade da precipitação pluvial na Paraíba é menor no Litoral e Brejo e maior no Sertão, durante o ano e trimestre seco, enquanto durante o trimestre chuvoso a variabilidade é maior no Litoral e Brejo e menor no Sertão.

\section{Dados utilizados}

Para o desenvolvimento deste estudo, utilizaram-se registros mensais de dados de precipitação, para os 48 municípios pertencentes à região do Sertão paraibano, compreendendo o período de 1979-2013, provenientes do CPC (Climate Prediction Center), centro pertencente ao NCEP (National Centers for Environmental Prediction). Dados validados por Melo (2015) que afirma que, os dados do CPC conseguiram representar bem o período chuvoso, que se dá entre fevereiro e abril, apresentando uma margem de erro relativa que não ultrapassou $10 \%$ nestes meses, e o erro encontrado para o total anual foi de $3,4 \%$.

\section{Índice de Anomalia de Chuva (IAC)}

O Índice de Anomalia de Chuva (Rainfall Anomaly Index) analisa a frequência em que ocorrem anos secos e anos chuvosos e a intensidade do evento. Foi desenvolvido por Rooy (1965) que, incorpora um procedimento de classificação para ordenar magnitudes de anomalias de precipitações positivas e negativas. A metodologia de Rooy (1965) foi adaptada para o Nordeste do Brasil por Freitas (2004), no qual se analisa há variabilidade climática através da elaboração dos índices climáticos espacializados, tanto no tempo como no espaço, identificando períodos considerados extremamente úmidos ou secos.

O IAC é calculado na escala de tempo semanal, mensal ou anual. A escolha da escala de tempo é feita com base na distribuição da precipitação. Em áreas com longos períodos de seca deve ser usada uma escala de tempo maior, do que em áreas com curtos períodos de seca.

O Índice propõe tornar o desvio da precipitação em relação à condição normal de diversas regiões passíveis de comparação (ROOY, 1965). O procedimento para o cálculo do IAC é descrito a partir das equações 1 e 2 . Se o valor de $\mathrm{N}-\overline{\mathrm{N}}$ for maior que zero, utiliza-se a equação 1 , se o resultado for negativo a equação 2 .

$$
\begin{gathered}
\mathrm{IAC}=3 \cdot\left[\frac{(\mathrm{N}-\overline{\mathrm{N}})}{[(\overline{\mathrm{M}}-\overline{\mathrm{N}})]}\right] \\
\mathrm{IAC}=-3 \cdot\left[\frac{(\mathrm{N}-\overline{\mathrm{N}})}{[(\overline{\mathrm{X}}-\overline{\mathrm{N}})]}\right]
\end{gathered}
$$

Em que: $N$ - Precipitação mensal ou anual atual (mm/mês); $\overline{\mathrm{N}}$ - Precipitação média mensal ou anual da série histórica (mm/mês); $\overline{\mathrm{M}}$ - Média das dez maiores precipitações mensais ou anuais da série histórica $(\mathrm{mm} / \mathrm{mês}) ; \overline{\mathrm{X}}$ - Média das dez menores precipitações mensais ou anuais da série histórica (mm/mês).

As anomalias positivas representam valores acima da média histórica e anomalias negativas, valores abaixo da média histórica. Os valores do índice são ordenados em um esquema de classificação em categorias como mostrado na Tabela 1, variando de extremamente chuvoso a extremamente seco.

Assis et al. (2013) afirmam que, essa metodologia vem sendo bastante difundida no Nordeste brasileiro para caracterizar os períodos extremos, assim como as diferentes intensidades desses eventos na escala espaço-temporal. Um ponto crucial no emprego desse índice, bem como qualquer outro índice climático, consiste na escolha do patamar a ser estabelecido para a definição de um período de seca. Entretanto, Freitas (2004 e 2005) observou que, com base no mesmo, é possível fazer uma comparação das condições atuais de precipitação em relação aos valores históricos, 
servindo ainda para avaliar a distribuição espacial do evento, consoante sua intensidade.

Os valores do Índice de Anomalia de Chuva gerados a partir dos dados de precipitação anual para o período chuvoso e o período de estiagem para cada município, foram organizados em tabelas do Software Microsoft Office Excel e posteriormente importados em tabela para o Software Surfer 10.Na Tabela 1, além dos dados do Índice de Anomalia de Chuva (IAC) de cada ponto amostral, foram inseridas as médias interanual e as coordenadas geográficas, o que possibilitou a confecção da espacialização do IAC para a microrregião do Sertão Paraibano.

Tabela 1.Classificação da pluviosidade baseado no Índice de Anomalia de Chuva

\begin{tabular}{c|c}
\hline CLASSIFICAÇÃo DA & ÍNDICE DE ANOMALIA DE \\
PLUVIOSIDADE & CHUVA \\
\hline Extremamente chuvoso & Acima de 4,00 \\
Muito Chuvoso & Entre 2 e 4 \\
Chuvoso & Entre 0 e 2 \\
Normal & Igual a 0 \\
Seco & Entre 0 e - 2 \\
Muito Seco & Entre - 2 e -4 \\
Extremamente Seco & Menor que - 4 \\
\hline
\end{tabular}

Fonte: Adaptado de Marcuzzo et al., 2010.

\section{RESULTADOS E DISCUSSÃO}

No painel têmporo-espacial observa-se a variabilidade dos totais pluviométricos anuais e para o período chuvoso, com o intuito de verificar possíveis padrões predominantes, uma perspectiva geral, representado pelas chuvas nos 35 anos, para os municípios que compõem a microrregião do Sertão paraibano (Figura 2).

Seguindo uma visão geral, na Figura 2, evidencia-se a variação têmporo-espacial anual das chuvas entre 200 e 2000 $\mathrm{mm}$, o que demonstra a acentuada variabilidade, confirmando assim, períodos com excesso e déficit de chuva, fato esse que confirma a necessidade de estudos sobre a variação desses extremos.

Pode-se verificar ainda na Figura 2, o ano que apresentou maior volume, que foi o de 1985, entretanto percebe-se que foram 3 anos de chuvas intensas, que diminuíram a atividade até o ano de 1993, em que observa-se precipitações muito baixas. Depois há o acometimento no aumento da quantidade de chuvas anuais com outro déficit no ano de 1998. Após essa data, percebem-se valores anuais de precipitação maiores, que oscilam até a possibilidade de verificar-se no ano de 2012, valor bem abaixo da média, que é de $306 \mathrm{~mm}$ para a região. Os anos mais secos, de acordo com a Figura 2, são 1993, 1998 e 2012. Apesar de ser perceptível que existem oscilações de valores de precipitação entre as localidades, nota-se que eles são bem sutis em relação à variação anual.

Figura 2. Painel têmporo-espacial da precipitação anual para as 48 cidades do Sertão Paraibano (1979 - 2013).
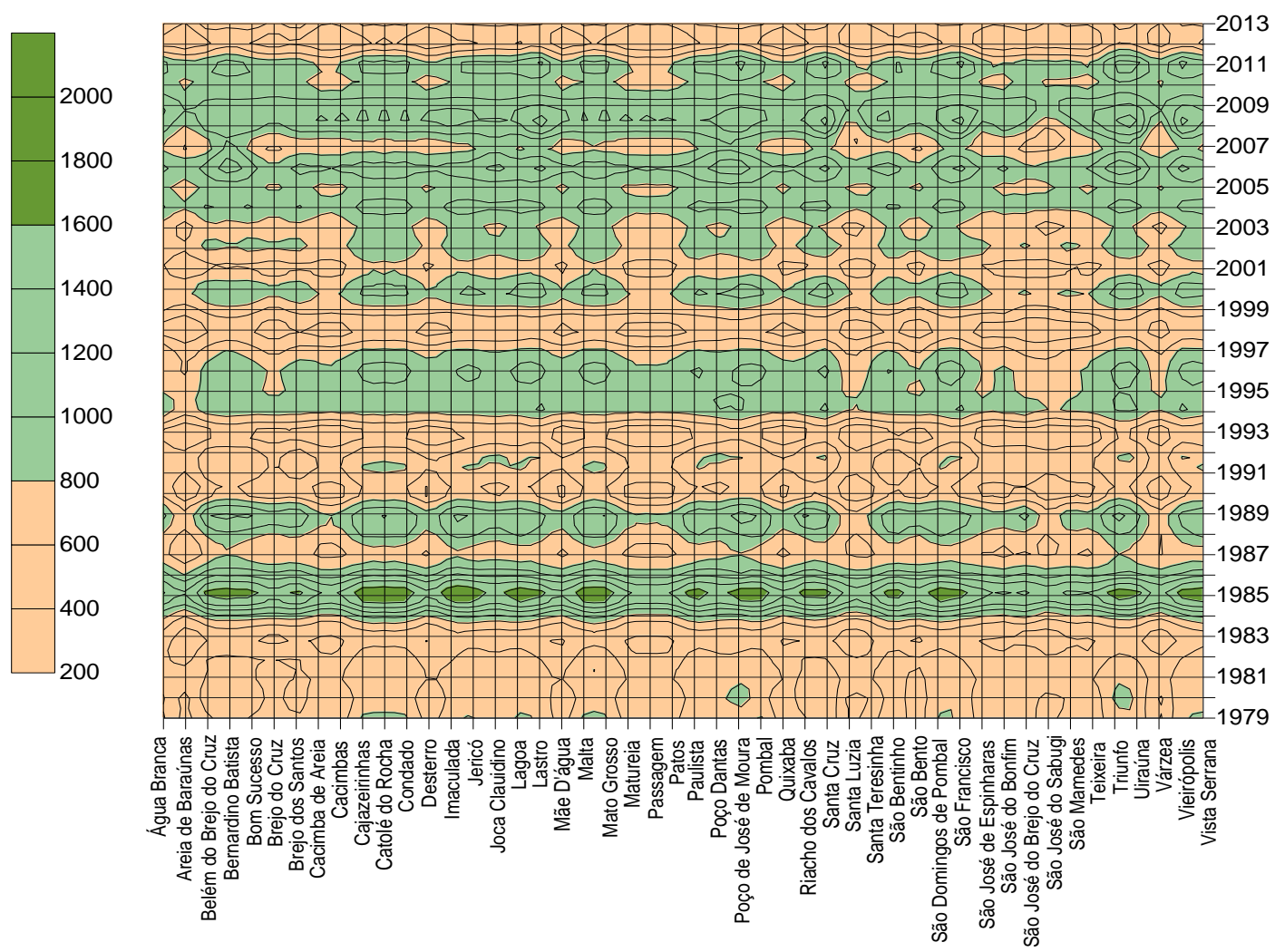

A análise do painel têmporo-espacial da precipitação mês a mês para cada localidade, mostra que o período chuvoso para a região do sertão paraibano inicia-se no inicio do ano e vai até no máximo o mês de maio, com valores que chegam a $200 \mathrm{~mm}$. Após esses meses percebem-se os pequenos valores de precipitação que não ultrapassam 20 mm, para todas as cidades (Figura 3). Essa distribuição das chuvas concorda com a encontrada por Melo (2015). 
Figura 3. Painel têmporo-espacial da precipitação mensal para as 48 cidades do Sertão Paraibano (1979 - 2013).

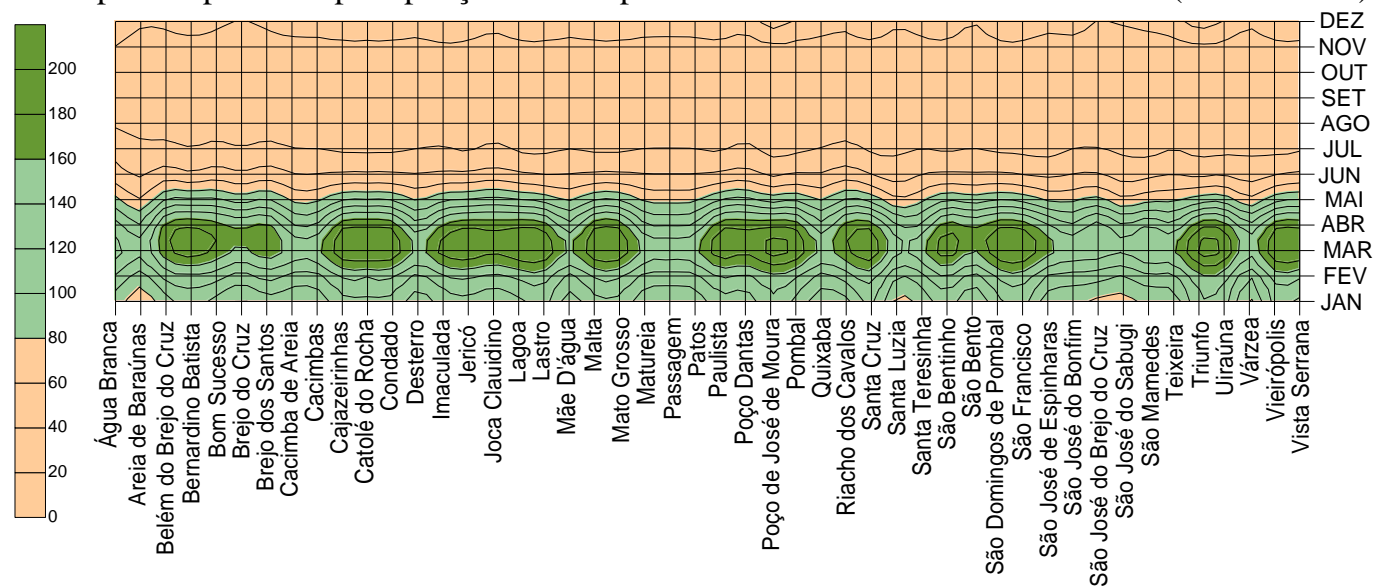

Com o intuito de verificar como a precipitação na região se comporta no espaço, foram elaboradas figuras para analisar essa distribuição espacial do sertão paraibano. A variabilidade espacial climatológica da precipitação anual apresenta uma variação no sentido leste - oeste, estando os maiores valores concentrados na parte oeste do sertão paraibano (Figura 4a), com um gradiente variando entre 540 $\mathrm{mm}$ a $890 \mathrm{~mm}$.

$\mathrm{Na}$ Figura $4 \mathrm{~b}$ apresenta o comportamento da precipitação anual média para os anos classificados como extremamente chuvoso, muito chuvoso e chuvoso (1985, 1986, 1989, 2006, 2008, 2009 e 2011). Observa-se que a figura é concordante com a climatologia anual, com os maiores valores de precipitação na parte oeste da região, na cidade de Triunfo, com 1336,9 mm. Destaca-se a quantidade de chuva que exibe valores bem mais elevados, apresentando uma média de 1180,4 mm, nestes anos chuvosos, correspondendo a um aumento médio de $152 \%$. Todavia para os anos classificados como secos - 06 anos (1983, 1990, 1993, 1998, 2001, 2012) - a variação espacial também está de acordo com o encontrado anteriormente, pois nestes anos a precipitação é muito reduzida (50\%), o máximo verificado é inferior ao mínimo da climatologia, vide Figura 4c e 4a.

A identificação dos eventos extremos conforme a metodologia do IAC pode ser observada na Figura 5, onde se evidencia a configuração de grande variabilidade interanual da precipitação, já esperada na região, e dos eventos extremos (secos e chuvosos). A precipitação foi classificada nas categorias descritas na metodologia, a saber: extremamente chuvoso, muito chuvoso e chuvoso (valores positivos do IAC) e extremamente seco, muito seco e Seco (valores negativos do IAC) para o período em estudo (1979 - 2013).

É importante ressaltar que, a precipitação média anual esperada para a região é $776 \pm 284 \mathrm{~mm}$, conforme os cálculos realizados e concordantes com os resultados encontrados por Melo (2015) e com os estudos de Silva (2007). O maior valor da precipitação anual foi verificado no município de Poço de José de Moura $(910,7 \mathrm{~mm})$ a oeste e o menor com 549,8 $\mathrm{mm}$ em Areia de Baraúnas, a leste. A amplitude observada nas duas localidades, aproximadamente $361 \mathrm{~mm}$, evidencia a variabilidade existente na região.

Figura 4 Distribuição espacial da precipitação anual: a) climatologia da região (1979-2013), b) Para os anos de eventos chuvosos e c) Para os anos de eventos secos

a) CLIMATOLOGIA

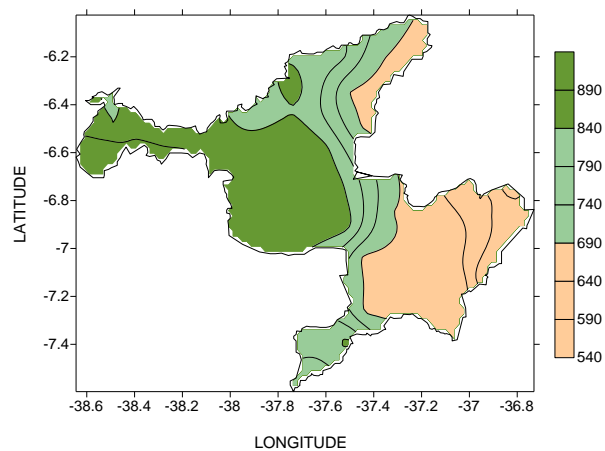

b) EVENTOS CHUVOSOS

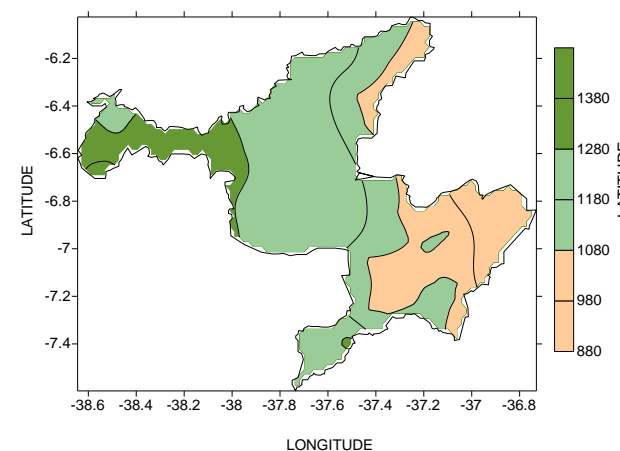

c) EVENTOS SECOS

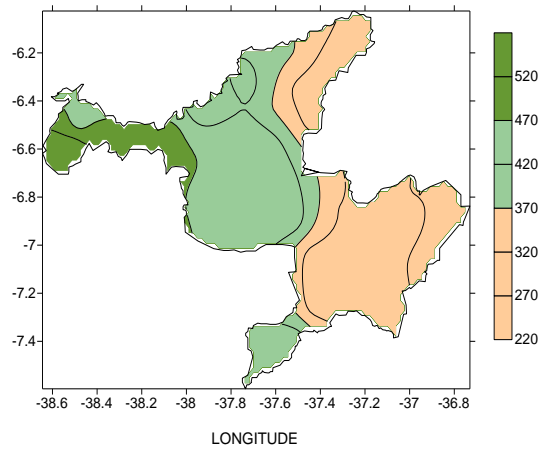

Verificou-se a ocorrência de 19 anos com desvios negativos, variando entre as classes de extremamente seco, muito seco e seco, correspondendo a 54,3\% dos anos. Os desvios positivos apresentaram-se em 16 anos (45,7\%). Segundo os valores do IAC, o ano mais extremo foi o de 1985 $(1642,16 \mathrm{~mm})$, apresentando uma precipitação bem acima da média climatológica, com um IAC de 7,6, classificado como um ano extremamente chuvoso, o aumento das chuvas chegou a aproximadamente $112 \%$ da média (Figura 5).

Com relação aos menores índices, destacam-se os anos de 1993 e 2012 (282 mm; 306 mm), classificados como extremamente secos, nesses anos a redução foi maior que $60 \%$ da média esperada para o ano na região (Figura 5). Segundo o IA, os eventos anômalos apontam que, no período 
em estudo têm-se maiores eventos extremos de seca, com 3 eventos, contra 1 extremamente chuvoso. Todavia, se quantificar o índice em termos da variação acima e abaixo do eixo, verifica-se que temos praticamente o mesmo percentual, ou seja, $45,7 \%$ o IAC apresenta-se positivo e o restante negativo, tal como verificado por Sena et al. (2015).

É possível constatar algumas características no decorrer do tempo, ciclos secos e chuvosos, que duram em média $3-4$ anos. A exceção ocorre no período entre 2003 e 2010, em que são observados anos extremamente chuvoso e chuvoso, após esse período inicia-se períodos na classificação seco (Figura 5).

Para melhor analisar o grau de severidade dos eventos extremos interanual, sendo que na microrregião praticamente só chove nos primeiros meses do ano, sendo 59\% dessa precipitação concentrada nos meses de fevereiro, março e abril, considerados período chuvoso (MELO et al., 2015). Portanto, foi calculado o índice de anomalia de chuva para esses meses.

Verifica-se na Figura 6, que o comportamento para o período chuvoso é semelhante ao período interanual (Figura 5). O maior desvio foi no ano de 1985 e o menor no ano de 1993. Os anos de 1980, 1981, 1982, 1992 e 1995 os IAC's foram muito próximos de zero, podendo ser considerados como normais. No período de 1984 a 1989, os anos foram classificados como extremamente chuvoso, muito chuvoso e chuvoso. Dessa forma, temos os meses de fevereiro a abril que contribuíram de forma significativa para a anomalia positiva da precipitação anual.

No entanto de 1990 a 2004 ocorrem mais desvios negativos, apenas os anos de 1996 e 2000 apresentaram desvios positivos, pois de 2006 a 2009 ocorre o inverso, apenas desvios positivos, de 2010 a 2013 desvios negativos, com exceção do ano de 2010 com desvio positivo, classificado na categoria de chuvoso. Com isso, observa-se que, ocorre uma variação climática na precipitação da região, em alguns anos do período chuvoso contribuindo para a região e em alguns anos não (Figura 6).

Com a intenção de observar se os demais meses, que não compõem o período chuvoso influenciam na precipitação dos eventos extremos, calculou-se o IAC para os meses de maio a janeiro, ou seja, para os 9 meses que excluímos do período chuvoso. Nota-se que os anos dos eventos chuvosos citados acima, tiveram uma contribuição significativa dos demais meses, sendo que quase todos foram classificados como muito chuvoso, com exceção apenas de 1986 que apresentou um IAC de 0,1 . Os anos de eventos secos não apresentaram contribuição dos meses que não compõe o período chuvoso, como observado na Figura 7.

Figura 5. Índice de Anomalia de Chuva para o período interanual do Sertão Paraibano.

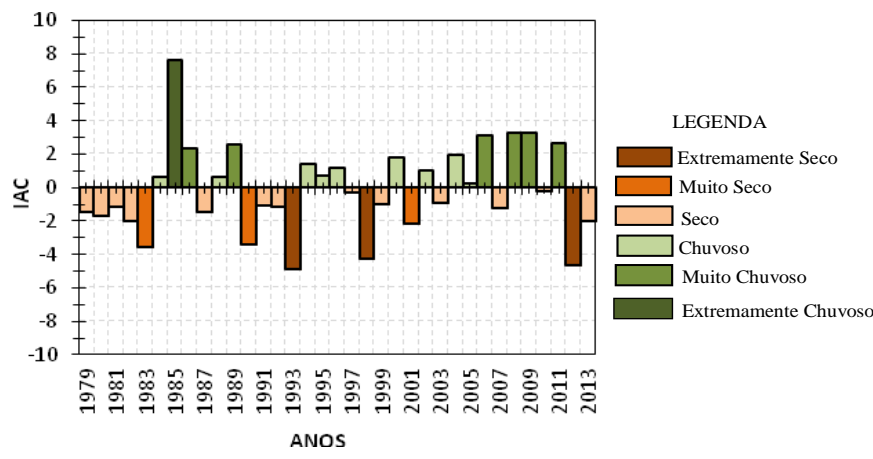

Assim, comparando a Figura 6 com a 7, destaca-se o ano de 2004, no período chuvoso e classificado na categoria seco, na Figura 7 classificado como extremamente chuvoso.

Figura 6. Índice de Anomalia de Chuva para o período chuvoso do Sertão Paraibano.

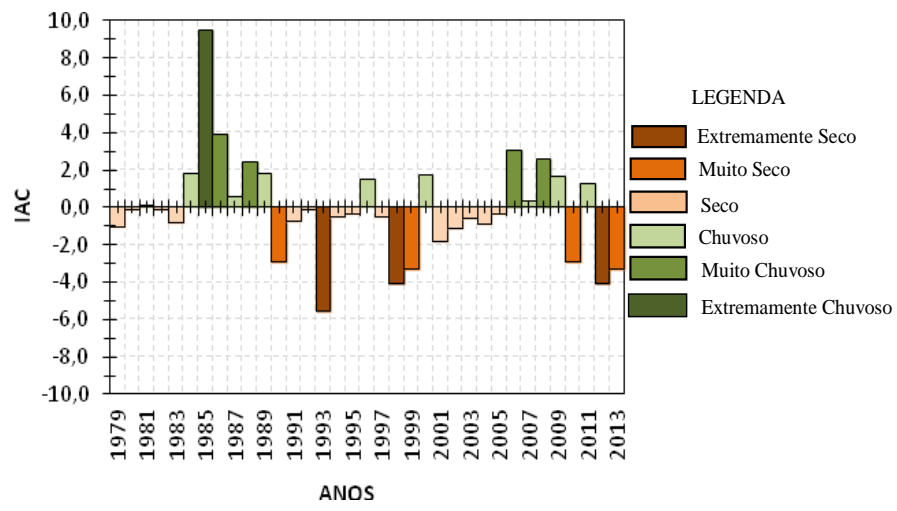

Figura 7. Índice de Anomalia de Chuva para os meses que não compõe o período chuvoso da região

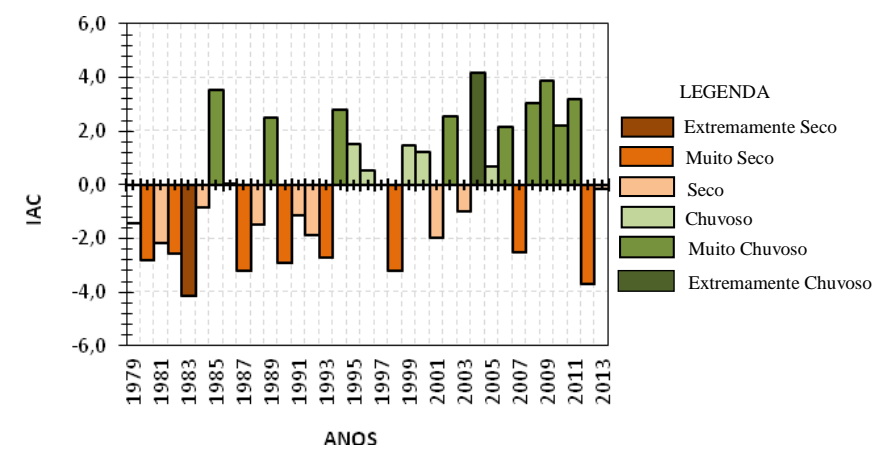

\section{CONCLUSÕES}

A distribuição têmporo-espacial permite uma boa visualização tanto no tempo quanto no espaço do comportamento das precipitações. A região é bastante homogênea em relação aos eventos extremos, ou seja, os anos chuvosos ou secos, quando ocorrem atingem toda a microrregião. No painel em escala anual têm-se um período bem pequeno que considera-se como período chuvoso, após este período que ocorre no inicio do ano, a precipitação média é muito pequena.

O método IAC utilizado para identificar os extremos secos e chuvosos mostrou simplicidade na realização e apresentou êxito, podendo ser utilizado como uma ferramenta para analise climática. Não obstante, através desse tipo de monitoramento é possível gerar prognósticos e diagnósticos climatológicos regionais.

Para a série de 35 anos de dados de precipitação para a microrregião do Sertão Paraibano, verificou-se que 19 anos apresentaram desvios negativos $(54,3 \%)$ e 16 anos desvios positivos $(45,7 \%)$. Destes, 3 eventos classificados como extremamente seco, com redução de aproximadamente $60 \%$ da média esperada para o ano, e apenas um extremamente chuvoso, 1985, que apresentou maior índice pluviométrico registrado no período de 1979 a 2013, com um aumento de $112 \%$ em relação a média climatológica da região.

O período chuvoso da região contribuiu de forma significativa nos eventos chuvosos, entretanto, para os eventos secos não houve nenhuma contribuição. 
A variação espacial da precipitação na região tanto para a climatologia quanto para as composições dos anos selecionados, como secos e chuvosos, apresentam-se distribuídos no sentido Leste-Oeste, com amplitudes altas, comprovando a variação espacial.

\section{REFERÊNCIAS}

ARAÚJO, L. E.; MORAES NETO, J. M.; SOUSA, F. A. S. Classificação da precipitação anual e da quadra chuvosa da bacia do rio Paraíba utilizando o Índice de Anomalia de Chuva (IAC). Revista Ambiente \& Água - $\mathrm{Na}$ Interdisciplinary Journal of Applied Science, Taubaté, v.4, n.3. p.93-110. 2009.

ASSIS, J. M. O.; SOUZA, W. M.; SOBRAL, M. C. M.; MELO, G. L.; IRMAO, R. A. Índice de anomalia de chuva (IAC) como indicador para análise da variabilidade climática na bacia hidrográfica do Rio Pajeú-PE. In: XX Simpósio Brasileiro de Recursos Hídricos. Bento Gonçalves - RS. 2013.

BRASIL, Ministério do Meio Ambiente. Mudanças climáticas e suas implicações para o Nordeste. relatores: Otamar de Carvalho; Nilson Holanda. Brasília: MMA. 232 p. 2005

CHECHI, L.; SANCHES, F. O. O Uso do Índice de Anomalia de Chuva (IAC) na avaliação do Fenômeno do El Niño Oscilação Sul (ENOS) no Alto Uruguai Gaúcho entre 19572012. Revista Brasileira de Geografia Física, v. 6, n. 6, 2013.

FRANCISCO, P. R. M. Classificação e mapeamento das terras para mecanização do Estado da Paraíba utilizando sistemas de informações geográficas. 122f. Dissertação (Manejo de Solo e Água). Centro de Ciências Agrárias, Universidade Federal da Paraíba. Areia, 2010

FREITAS, M. A. S. A Previsão de secas e a gestão hidroenergética: o caso da Bacia do Rio Parnaíba no nordeste do Brasil. In: Seminário Internacional Sobre Represas y Operación de Embalses. Puerto Iguazú. v. 1.p.1-1. 2004.

FREITAS, M. A. S. Um sistema de suporte á decisão para o monitoramento de secas meteorológicas em regiões semiáridas. Revista Tecnologia, Fortaleza, v. suplem., p. 8495, 2005.

GEO BRASIL. Recursos hídricos: componente da série de relatórios sobre o estado e perspectivas do meio ambiente no Brasil. Ministério do Meio Ambiente; Agência Nacional de Águas; Programa das Nações Unidas para o Meio Ambiente. Brasília: Ministério do Meio Ambiente; ANA. GEO Brasil Série Temática: GEO Brasil Recursos Hídricos, 264 p. 2007.

GONÇALVES, N. M. S. Impactos pluviais e desorganização do espaço urbano em Salvador. In: MENDONÇA, F.; MONTEIRO, C.A.F. (Org.). Clima urbano. 2. ed. São Paulo: Contexto, 2013

GONÇALVES, W. A.; CORREIA, M. F.; ARAÚJO, L. E.; DA SILVA, D. F.; ARAÚJO, H. A. Vulnerabilidade climática do nordeste Brasileiro: uma análise de eventos extremos na Zona Semiárida da bacia hidrográfica do São Francisco. In: Congresso Brasileiro de Meteorologia, Florianópolis-SC. 2006.

IBGE. Instituto Brasileiro de Geografia. Disponível em: < www.ibge.gov.br/home/ >. Acesso em: 29 de maio de 2016.

LIMEIRA, R. C. Variabilidade e Tendência das Chuvas no Estado da Paraíba. Universidade Federal de Grande, Unidade Acadêmica de Ciências Atmosféricas, Centro de Tecnologia e Recursos Naturais, Programa de Pós graduação em Meteorologia. Dissertação de mestrado, 2008.

LOUREIRO, R. S. de; SARAIVA, J. M.; SARAIVA, I.; SENNA, R. C.; FREDO, A. S. Estudo dos eventos extremos de precipitação ocorridos em 2009 no estado do Pará. Revista Brasileira de Meteorologia, São Paulo, v. 29, n. esp., p. 83-94, dez. 2014

MARCUZZO, F.F.N.; GOULARTE, E.R.P.; MELO, D.C.R. Mapeamento Espacial, Temporal e Sazonal das Chuvas no Bioma Amazônico do Estado do Tocantins. In: X Simpósio de Recursos Hídricos do Nordeste. 2010.

MARENGO, J. A. Mudanças climáticas e eventos extremos no Brasil. Fundação Brasileira para o Desenvolvimento Sustentável - FBDS. 2010. Disponível em: < http://www.fbds.org.br/cop15/FBDS_MudancasClimaticas.pd f >. Acesso em: 29 de maio de 2016.

MARENGO, J. A. Mudanças climáticas globais e regionais: Avaliação do clima atual do Brasil e projeções de cenários climáticos do futuro. Revista Brasileira de Meteorologia, v.16, p. 1-18. 2002.

MELO, J. S. Avaliação dos dados de precipitação derivados do Climate Prediction Center (CPC) no sertão Paraibano e a influência dos oceanos. TCC (Graduação em Engenharia de Biossistemas). UFCG - Campus Sumé. p. 36. 2015.

PARAÍBA. Secretaria de Estado da Ciência e Tecnologia e do Meio Ambiente. Agência Executiva de Gestão de Águas do Estado da Paraíba, AESA. PERH-PB: Plano Estadual de Recursos Hídricos: Resumo Executivo \& Atlas. Brasília, DF, 112 p. 2006.

REPELLI, C. A.; FERREIRA, N. S.; ALVES, J. M. B.; NOBRE, C. A. Índice de anomalia de precipitação para o Estado do Ceará. In: X Congresso Brasileiro de Meteorologia e VII Congresso da Flismet. Brasília. 1998.

ROOY, M. P. VAN. A Rainfall Anomaly Index Independent of Time and Space. Notes, v.14, p. 43, 1965.

SANCHES, F. O.; VERDUM, R.; FISCH, G. O índice de anomalia de chuva (IAC) na avaliação das precipitações anuais em Alegrete/RS (1928-2009). Caminhos de Geografia. v.15, n.51, p. 73-84. 2014.

SENA, J. P. O.; MELO, J. S.; LUCENA, D. B.; MELO, E. C. S. Técnica dos quantis para caracterização de eventos extremos de precipitação na microrregião do Sertão Paraibano 
(1995-2012). In: Terra: Saúde Ambiental e Soberania Alimentar. Ituiutaba-MG: Barlavento. v. I, p. 806-817. 2015.

SILVA, J. B.; BASGALUPP, M. P.; PAZ, S. R. Comportamento das precipitações pluviais mensais em Pelotas, Rio Grande do Sul. Revista Brasileira de Agrometeorologia, v. 13, n. 01, p. 155-159. 2005.

SILVA, A. L.; ROVERATTI, R.; REICHARDT, K.; BACCHI, O. O. S.; TIMM, L. C.; BRUNO, I. P.; OLIVEIRA, J. C. M.; DOURADO-NETO, D. Variabilidade do componentes do balanço hídrico de uma cultura de café no Brasil. Scientia Agricola, Piracicaba, v.63, n.2, p.105-114, 2006.

SILVA, L. L. Precipitações Pluviais da Pré-estação Chuvosa no Período Chuvoso e Suas Influências na Produtividade
Agrícola da Paraíba. Dissertação de Mestrado em Meteorologia. Universidade Federal de Campina Grande, 114 p. 2007.

SILVA, V. P. R.; CAVALCANTI, E. P.; NASCIMENTO, M. G.; CAMPOS, J. H. B. C. Análises da precipitação pluvial no Estado da Paraíba com base na teoria da entropia. Revista Brasileira de Engenharia Agrícola e Ambiental. v. 7, n.2, p 269-274. 2003.

WANDERLEY, L. S. A.; MORETTI, R. C.; SILVA, A. C. Variabilidade de pluviométrica e as lavouras sazonais no município de Taperoá, Paraíba. Revista Geonorte, Edição especial 2, V.2, N. 5, p.1181 - 1190, 2012. 